\title{
EFFECT OF ANNEALING ON MAGNETIC AND STRUCTURAL PROPERTIES OF THE NANOCRYSTALLINE Fe-Mn-Al ALLOYS
}

\author{
K. Tarigan*, and D. Sebayang \\ Department of Mechanical Engineering, Mercu Buana University, West Jakarta 11650, INDONESIA
}

\begin{abstract}
In this work, the formations of $\mathrm{Fe}_{55} \mathrm{Mn}_{10} \mathrm{Al}_{35}$ nanocrystalline alloys were made by using mechanical alloying (MA) technique with the milling time of $24 \mathrm{hrs}$ and then annealed at 300,500 , and $700^{\circ} \mathrm{C}$. The sizes and the morphology of the particles were checked by using a Scanning Electron Microscope (SEM). The magnetic properties were characterized by using a Vibration Sample Magnetometer (VSM), and it give results both of the magnetic saturation $(M s)$ and Coercivity $(H c)$ are decreased respect to annealing temperatures. Last one; the structures were characterized by using an Extended X-ray Absorption Fine Structure (EXAFS) and X-Ray Diffraction (XRD). It give results that the structures were single phase at $24 \mathrm{hrs}$ milled and $300^{\circ} \mathrm{C}$ annealed, then the structure to be changed at 500 and $700^{\circ} \mathrm{C}$.
\end{abstract}

Keywords: $\mathrm{Fe}_{55} \mathrm{Mn}_{10} \mathrm{Al}_{35}$ nanocrystalline alloys, Annealing process, Magnetic and structures properties.

*Corresponding author: Tel. +62 21 5871335; Fax +62 215871335

E-mail address: kontan.tarigan@mercubuana.ac.id

\section{Introduction}

The alloy system Fe-Mn-Al belongs to large family of ternary alloys consisting of two $3 \mathrm{~d}$ transition metals and aluminum. These alloys are of technical and scientific interest because many different properties appear, depending on concentration and heat treatment. It was observed that these alloys can be prepared in crystalline and amorphous state. In many systems solid state reactions appear, such as order or disorder, influencing the physical properties. Especially magnetic properties depend very strongly on the crystalline structure, on the phase composition, and on the degree of order in such systems [1]. The study of melted Fe-Mn-Al disorder system is important due to the presence of competitive and diluted exchange interactions, which are allow to obtain different magnetic phase as paramagnetic, ferromagnetic, spin-glass, reentrant spin-glass an antiferromagnetic phases. The Fe-Mn-Al system which is present depending on composition is a semi-soft magnetic character [2].

Fe based metallic alloys have been extensively studied for the applications of the magnetic devices [3]. The ferromagnetic behavior observed in $\mathrm{Fe}$ based alloys is due to the presence of Fe clusters on grain boundaries or due to the formation of Fe-rich magnetic phases even if the starting composition is non-magnetic element rich composition. However, the mechanism formation of these phases, the influence of structural properties that gives rise to ferromagnetism and the effect of nano sized structure on the magnetic properties of these systems are far from being understood, especially [4].

Ternary Fe-Mn-Al system by MA technique has been studied in the literature, rarely. The former study achieved the effect of $\mathrm{Mn}$ or Al composition because the magnetic phase of $\mathrm{Fe}-\mathrm{Mn}-\mathrm{Al}$ system is dependent of structural changes with $\mathrm{Mn}$ or $\mathrm{Al}$ concentration. Especially, the microstructural change leads to a critical change of magnetic properties [3]. A few reports about the effects of temperature on the structural and magnetic properties of substances were exist.

In this work, we prepared and studied structural and magnetic properties of $\mathrm{Fe}_{55} \mathrm{Mn}_{10} \mathrm{Al}_{35}$ alloys by MA with the milling time $\left(t_{\mathrm{m}}\right)$ ranging from $1 \mathrm{hr}$ to $24 \mathrm{hrs}$, the results have reported by K. Tarigan et al. [5]. The samples of $24 \mathrm{hrs}$ were milled at 300,500 and $700^{\circ} \mathrm{C}$. Their magnetic and structural behaviors were studied by means of a SEM, VSM, XRD and EXAFS.

\section{Experimental}

$\mathrm{Fe}_{55} \mathrm{Mn}_{35} \mathrm{Al}_{10}$ nanocrystalline and amorphous alloys were prepared by MA using a SPEX 8000 mixer with stainless-steel balls and a stainless-steel vial. The starting mixture of $\mathrm{Fe}_{55} \mathrm{Mn}_{35} \mathrm{Al}_{10}$ was formed by using commercial powders of $\mathrm{Fe}(53 \mu \mathrm{m}$, 99.9\%), Mn (75 $\mu \mathrm{m}, 99.9 \%)$ and $\mathrm{Al}(53-106 \mu \mathrm{m}$, 99.9\%). The weight ratio of the ball-to-powder was 5:1 in an $\mathrm{Ar}$ ambient to avoid oxidation. 
$\mathrm{Fe}_{55} \mathrm{Mn}_{35} \mathrm{Al}_{10}$ alloys were mixed and ground of 24 hrs.

The annealing processes were $1 \mathrm{hr}$ warming up, $1 \mathrm{hr}$ annealing, and $1 \mathrm{hr}$ quenching in the air. The samples were annealed at 300,500 , and $700^{\circ} \mathrm{C}$.

After the preparation, the sizes and the morphologies of the particles were checked by using SEM. Then, the hysteresis loops were carried out by using a VSM. Based on these data were taken magnetization $(M s)$ and coercivity $(H c)$. The extended X-ray absorption fine structure (EXAFS) data were collected from accelerator which was operated at energy of $2.5 \mathrm{GeV}$ and a maximum current of $200 \mathrm{~mA}$. The EXAFS spectra were obtained at the $\mathrm{Fe}$ K-edge $(7112 \mathrm{eV})$ in the transmission mode at room temperature. The EXAFS data were analyzed by making use of the Athena software to mention the local structure of the samples. The structures of samples were obtained by using an X-ray diffractometer with the $\mathrm{Cu}-\mathrm{K}_{\alpha}$ radiation. Based on these data, the crystallite size of the samples was estimated by Scherrer equation. The structural properties are discussed in connection with the magnetic properties of the alloys.

\section{Result and Discussion}

Fig. 1 shows typical SEM images with a magnification of $100 \mathrm{k}$ and reveal the variation in the particle shape and the size of the nano-crystalline $\mathrm{Fe}_{55} \mathrm{Mn}_{10} \mathrm{Al}_{35}$ alloys after $24 \mathrm{hrs}$ of milling. The SEM study reveals that the particles present in the samples have quite similar shapes (others figures are not display here), with very small particles being located on the surfaces of big particles. There are large particles or agglomerates with spherical shapes. The particle sizes varied as we changed the annealing temperatures. The average particle sizes estimated from the SEM images increased respect to annealing temperatures.

Before structural investigations, we have studied magnetic properties based on hysteresis loop.

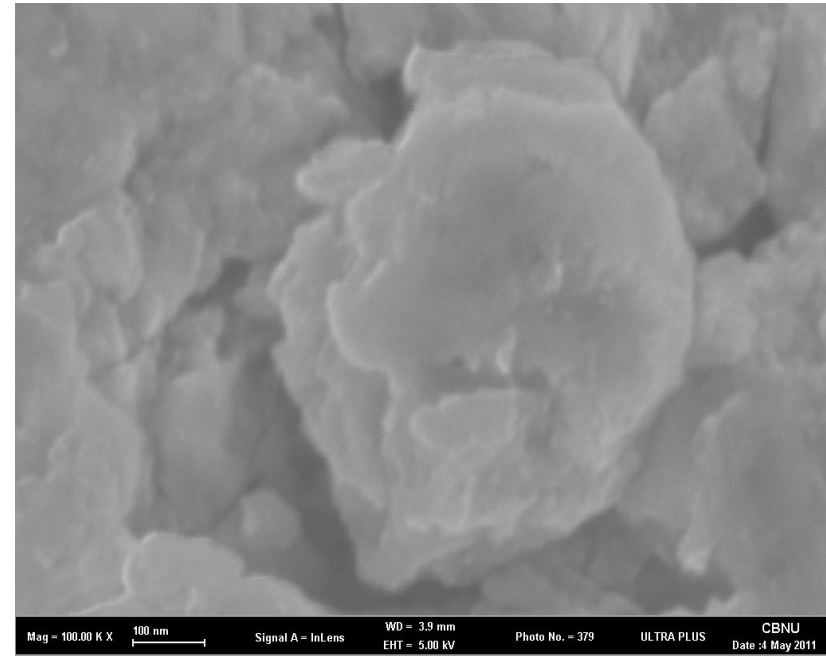

Fig. 1: Typical SEM image of nanocrystalline $\mathrm{Fe}_{55} \mathrm{Mn}_{10} \mathrm{Al}_{35}$ alloys with milling time $24 \mathrm{hrs}$

Both of the magnetization and coercivities of 500 and $700^{\circ} \mathrm{C}$ annealed are decreased around 10 $\mathrm{emu} / \mathrm{g}$ and $370 \mathrm{Oe}$, Fig. 3. The magnetization is decreased clearly reflects of the ferromagnetic component reduced in the sample. We can see that based on the XRD pattern, for annealed samples at 500 and $700^{\circ} \mathrm{C}$ are appeared new phase, Aluminum Manganese phase (P63mmc), Fig. 6.

In addition, we found the coercivity is reduced respect to annealing temperatures. Michael E. McHenry, et al proposed magnetic hardness (the coercivity, $\mathrm{Hc}$ ) is roughly inversely proportional to the grain size for grain sizes exceeding $\approx 0.1-1 \mu \mathrm{m}$ (where the grain size exceeds the domain wall thickness). In such cases grain boundaries act as impediments to domain wall motion, and thus finegrained materials are usually magnetically harder than large grain materials [6].

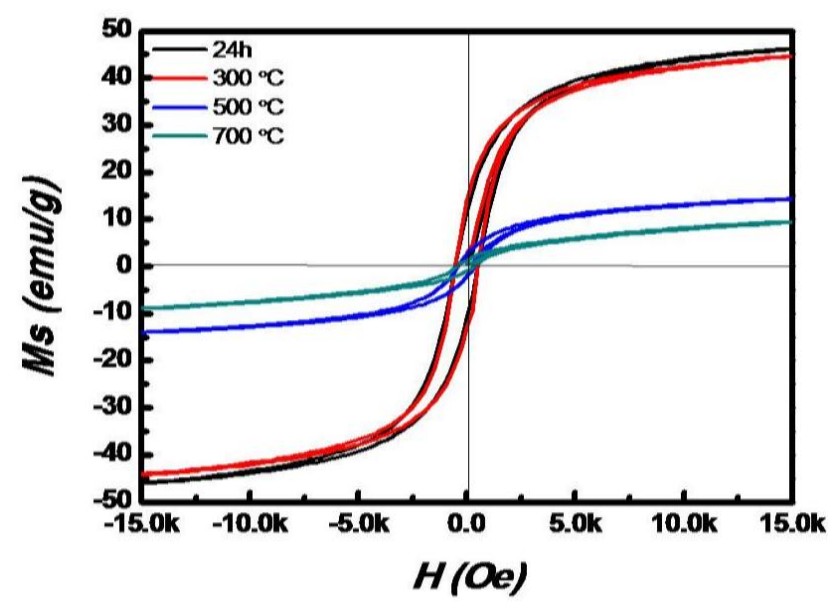

Fig. 2: Hysteresis loops for the nano crystalline $\mathrm{Fe}_{55} \mathrm{Mn}_{10} \mathrm{Al}_{35}$ samples with various annealing times which were recorded at $300 \mathrm{~K}$. 


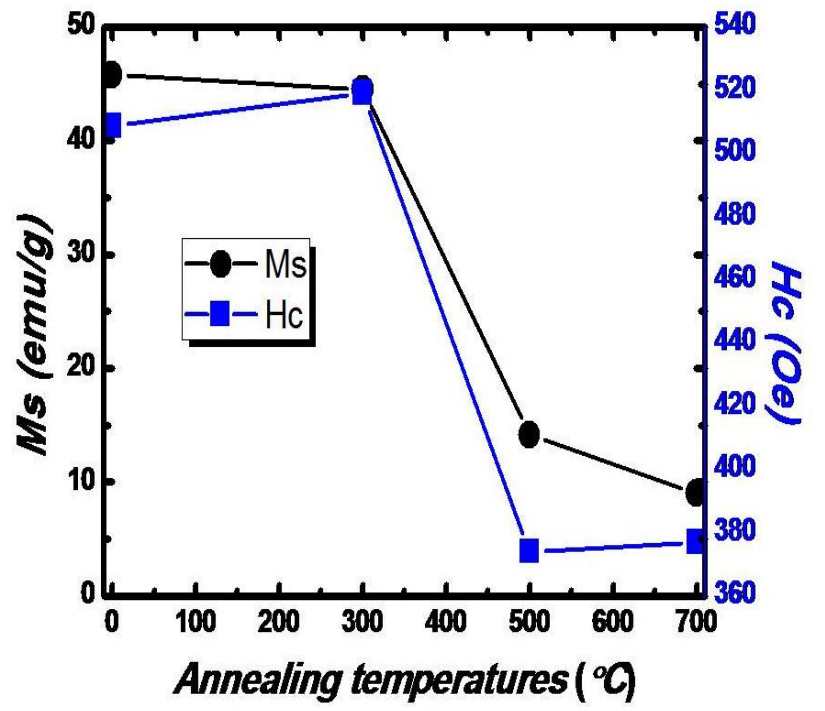

Fig. 3: Variation of magnetization and Coercivity of $\mathrm{Fe}_{55} \mathrm{Mn}_{10} \mathrm{Al}_{35}$ alloys with various annealing times.

In this work, the fact inversely, the grain size is increased respect to annealing temperature, so that the grain boundary area is decreased. Since the grain boundary is often associated with the pinning of domain walls, it follows that with increasing grain size, the pinning of domain wall motion decreases. Since coercivity $H c$ reflects amount and strength of pinning, we expect $H c$ to decrease for grain size increases. The results are in good agreement with the literature [7].

XANES and EXAFS can give information about the variation of local structure. We used the XANES to examine the variation of core electron configuration and EXAFS to examine the local structure around the $\mathrm{Fe}$ ions in the $\mathrm{Fe}_{55} \mathrm{Mn}_{10} \mathrm{Al}_{35}$ alloys of 24-hrs milled, 300, 500, and $700^{\circ} \mathrm{C}$ annealed samples.

Fig. 4 shows the normalized near edge spectra for the processed samples were similar to each other but above the edge the spectra gradually changed. This suggests that the electronic configuration for the Fe central atoms was unchanged but the surrounding around the $\mathrm{Fe}$ atoms ware changed during the mechanical alloying and annealing processed.

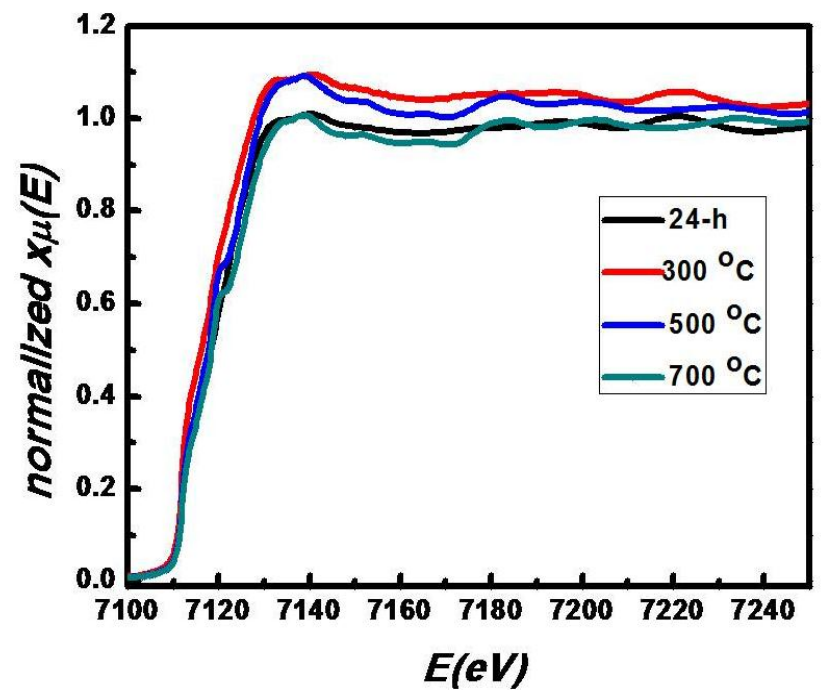

Fig. 4: The XANES spectra of 24 hrs milling, annealed of 300-, 500-, and $700^{\circ} \mathrm{C}$.

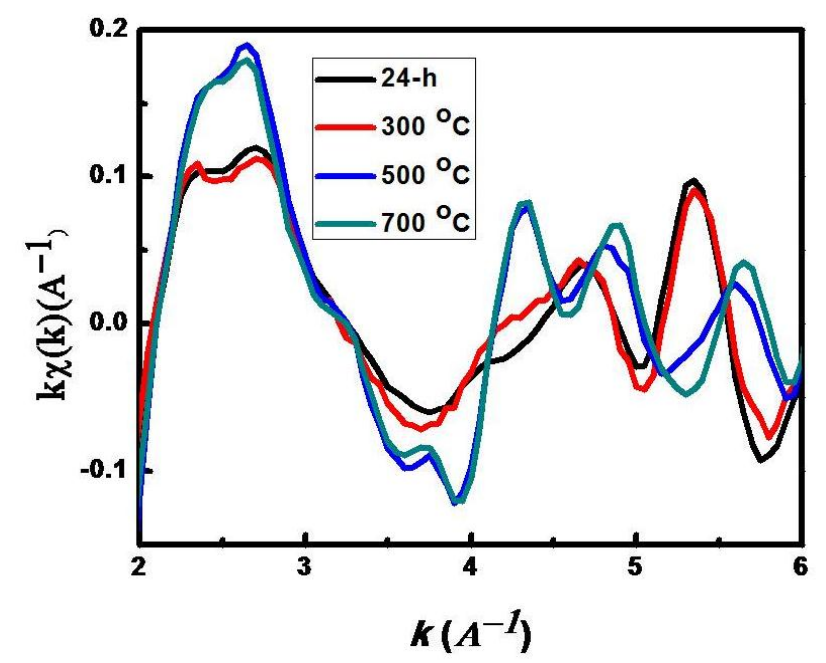

Fig. 5: The k-weighted EXAFS spectra of 24 hrs milling, annealed of 300-, 500-, and $700^{\circ} \mathrm{C}$

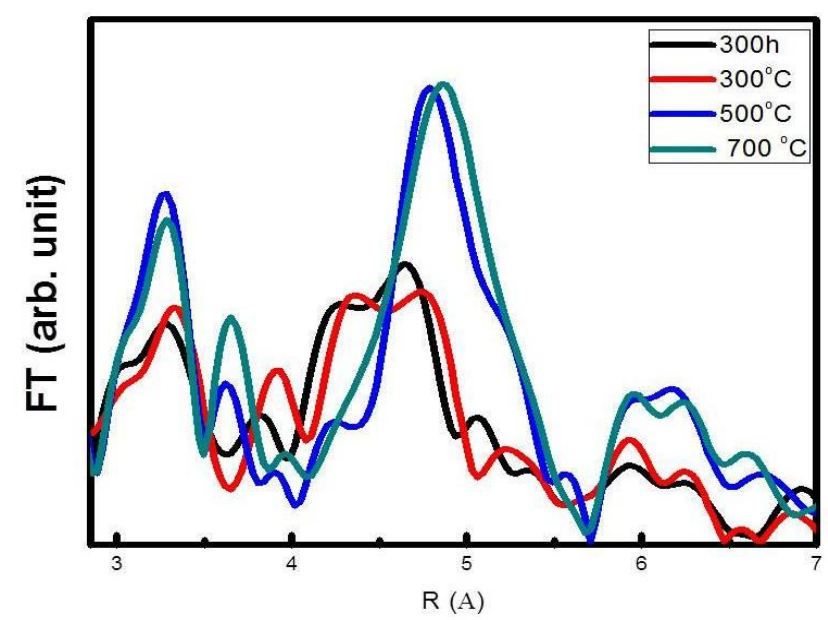

Fig. 6: The Fourier transformation of EXAFS spectra of 24 hrs milling, annealed of 300,500 , and $700^{\circ} \mathrm{C}$ 
Fig. 5 shows the EXAFS spectra of $\mathrm{Fe}_{55} \mathrm{Mn}_{10} \mathrm{Al}_{35}$ alloy for 24 hrs milled, 300-, 500-, and $700{ }^{\circ} \mathrm{C}$ annealed, respectively. The reduction of the amplitude is related to the disorder of local structure, and the variation of the phase is related to the change of chemical order [8]. Fig. 5 shows the significant changes in the amplitude and the phase took place after $500{ }^{\circ} \mathrm{C}$. Its mean there is a huge changed in local structural. The patterns can be divided by two types of local structures, i.e. the first type is the sample of 24-hrs milled and $300{ }^{\circ} \mathrm{C}$ annealed, and second type is 500 and $700^{\circ} \mathrm{C}$ annealed. That means each type has a different local structures.

Fig. 6 shows that the Fourier transform (FT) of EXAFS spectra measured at Fe K-edge. The radial atomic density van be seen in spectrum FT.Fig. 6 is consistent with Fig. 5 that local structure divided two groups.

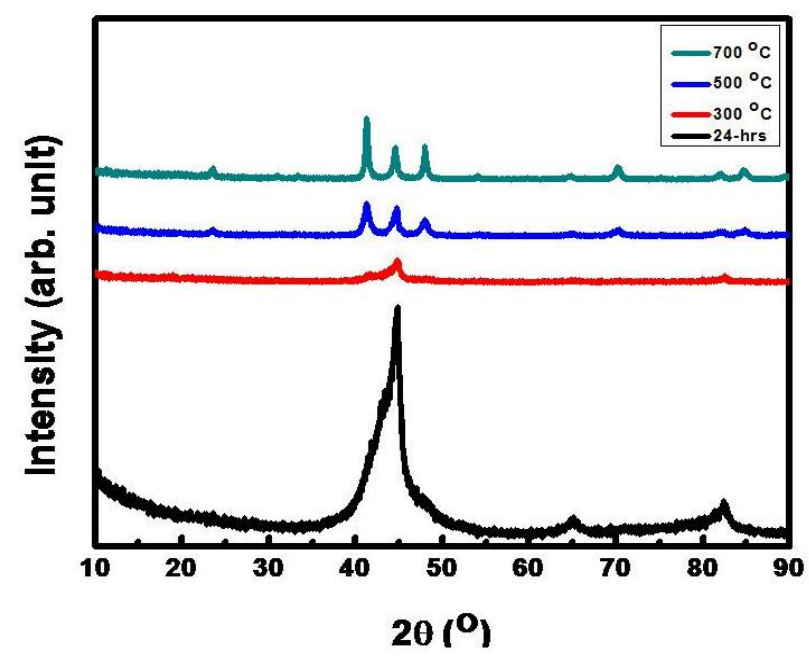

Fig. 7: The XRD patterns of 24 hrs milling, annealed of 300-, 500-, and $700^{\circ} \mathrm{C}$

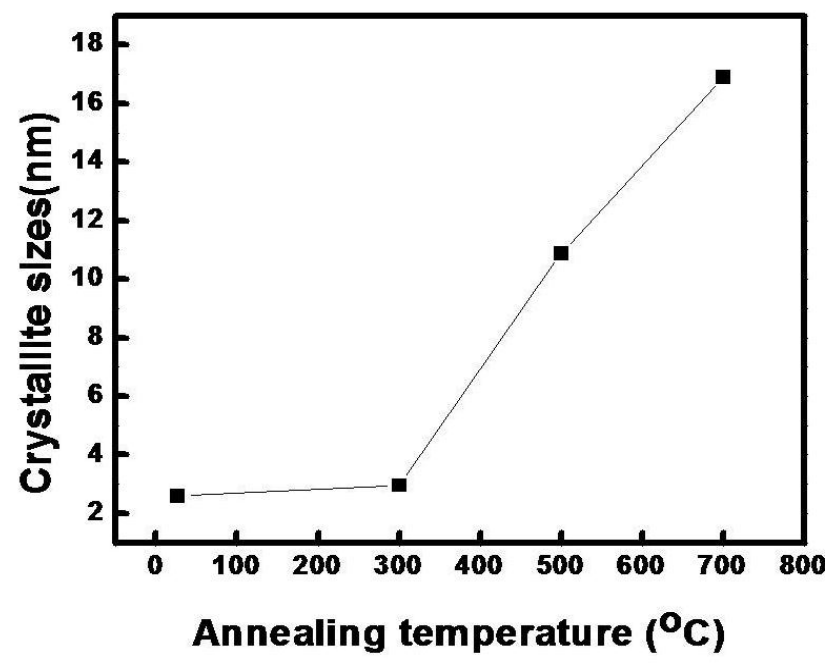

Fig. 8: Crystallite sizes of nano crystalline of $24 \mathrm{hrs}$ milling, annealed of 300-, 500-, and $700{ }^{\circ} \mathrm{C}$
Fig. 6 is consistent with Fig. 5 that local structure divided two groups, the samples of $24 \mathrm{~h}$ milled and $300^{\circ} \mathrm{C}$ in one group and 500 , and $700^{\circ} \mathrm{C}$ in another group.

Fig. 7 shows the alloy samples of $24 \mathrm{hrs}$ milled and $300^{\circ} \mathrm{C}$ annealed have repealed the single phase, bcc structure. For annealed samples of 500 and $700^{\circ} \mathrm{C}$ are not single phase, but appeared new phase, Aluminum Manganese (P63mmc).

Fig. 8 shows the crystallite sizes of $\mathrm{Fe}_{55} \mathrm{Mn}_{35} \mathrm{Al}_{10}$ alloys processed by the MA of $24 \mathrm{hrs}$ milled and 300,500 , and $700^{\circ} \mathrm{C}$ annealed, respectively. The crystallite size is calculated using the Scherrer method. The crystallite size is increased when the annealed temperature is increased. The estimated crystallite sizes were around 2.5 to $17.5 \mathrm{~nm}$, which corresponds to the nanostructure powder.

\section{Conclusion}

The nanocrystalline of $\mathrm{Fe}_{55} \mathrm{Mn}_{10} \mathrm{Al}_{35}$ alloys of 24 hrs milled have annealed at 300,500 , and $700^{\circ} \mathrm{C}$. The alloy samples of $24 \mathrm{hrs}$ milled and $300{ }^{\circ} \mathrm{C}$ annealed have repealed the single phase, bcc structure. For annealed samples of 500- and $700^{\circ} \mathrm{C}$ are not single phase, but appeared new phase, Aluminum Manganese (P63mmc). Both of the magnetic saturation $(M s)$ and Coercivity $(H c)$ are decreased respected to annealing temperature. The magnetization is decreased as reflects of the ferromagnetic component reduced in the samples. The coercivity is decreased because of grain boundary area decreases as effect of grain size increases respect to annealing temperatures.

\section{References}

[1] Heiko Bremers, Michael Fricke, and Jurgen Hesse, Structure and magnetic properties of FeMnAl alloys investigated by Mossbauer spectroscopy and $X$-ray diffraction, Hyperfine Interactions 94 (1994) 1855-1859.

[2] M. M. Rico, Liga E. Zamaro, G. A. Peres Alcazar, J. M. Gonzalez, and A. Hernando Jr., phys. Stat. sol. (b) 220, 445 (2000).

[3] F. Offi, W. Kuch, and J. Kirschner, "Structural and magnetic properties of $\mathrm{Fe} \mathrm{Mn}$ thin films on $\mathrm{Cu}(001)$ and on $\mathrm{Co} / \mathrm{Cu}(001)$," Phys. Rev.B, vol. 66, pp. 064419-1-064419-10, Aug. 2002.

[4] V. Sebastian, N. Lakshmi, and K. Venugopalan, "Correlation between microstructure and magnetic properties in mechanically alloyed nanogranular Fe Al ," Mater. Lett., vol. 66, pp. 4635-4638, Mar. 2007. 
[5] K. Tarigan, D. S. Yang, and S. C. Yu, Local Structure and Magnetic Properties of FeMnAl Nanocrystalline and Amorphous Alloys, Advanced Materials Research Vol. 277 (2011) pp 100-105

[6] Michael E. McHenry, Matthew A. Willard, David E. Laughlin, Amorphous and nanocrystalline materials for applications as soft magnets, Progress in Materials Science 44 (1999) 291-433.

[7] Abdul Samee Flaws Abdul Aziz, Variation of lattice parameter, average grain size, dielectric constant and saturation magnetization with different temperature for $0.30 \mathrm{Ni}_{0.7} \mathrm{Zn}_{0.3} \mathrm{Fe}_{2} \mathrm{O}_{4}+$ 0.70 PLZT composite by Co-precipitation method, Diyala Jorunal For Pure Sciences, Vol: 8 No: 3, July 2012

[8] D. S. Yang, et al., EXAFS Study for a Magnetic Shape Memory Alloy Ni-Mn-Ga, Journal of the Korean Physical Society, Vol. 50, No. 4, April 2007, pp. 1062 1067 